\title{
Pelatihan Penyulingan Serai Wangi dan Pembuatan Produk Turunan Menjadi Handsanitiser dan Sabun Cuci Tangan Kelompok Tani Desa Teluk Pambang, Bengkalis
}

\author{
Abdul Gafur*1, Endang Sriwahyuni2 \\ ${ }^{1}$ Teknik Mesin, Jurusan Teknik Mesin Politeknik Negeri Bengkalis, Indonesia \\ ${ }^{2}$ Akuntansi Keuangan Publik, Jurusan Administrasi, Politeknik Negeri Bengkalis, Indonesia \\ *e-mail: Abdulgafur@polbeng.ac.id ${ }^{1}$,Endangsriwahyuni@polbeng.ac.id ${ }^{2}$
}

\begin{abstract}
Abstrak
Dampak pandemi COVID-19 sangat memprihatinkan masyarakat baik dari segi pendapatan maupun dari segi kegiatan aktivitas sehari-hari. Salah satu upaya untuk mencegah mewabahnya COVID-19 adalah dengan mengikuti protokol kesehatan yang telah ditetapkan pemerintah, diantaranya menggunakan masker, hansanitiser, dan cuci tangan menggunakan sabun. Kelompok petani serai wangi berinisiatif untuk mengolah serai wangi hasil perkebunannya menjadi produk hansanitiser dan sabun cuci tangan. Permasalahan yang dihadapi kelompok petani serai wangi adalah minimnya pengetahuan tentang teknologi dan pengolahan minyak serai wangi, selain itu mahalnya harga alat destilasi yang bisa menghasilkan randemen minyak atsiri yang bagus. Oleh karena itu, solusi dari permasalahan yang dihadapi para petani serai wangi adalah dengan merancang dan membuat suatu teknologi mesin destilasi serai wangi dan produk turunannya untuk nantinya dijadikan sebagai media untuk pembuatan handsanitaiser dan sabun cuci tangan sebagai bentuk partisipasi dalam mencegah penyebaran COVID-19 di Desa Teluk Pambang. Pelatihan yang diberikan berupa penggunaan alat destilasi serai wangi yang telah dihibahkan, kemudian dilanjutkan dengan peltihan pembuatan handsanitiser dan sabun cuci tangan dengan bahan baku hasil destilasi serai wangi. Hasil pengabdian ini memperlihatkan semangat para petani danmasyarakat untuk membudidayakan serai wangi lebih banyak lagi, kelompok dan masyarakat bisa menggunakan alat destilasi dengan baik dan bisa juga mengolah produk turunan serai wangi menjadi handsanitiser dan sabun cuci tangan serta produk turunan lainnya.
\end{abstract}

Kata kunci: Alat Destilasi, Handsanitiser, Serai Wangi, Sabun Cuci Tangan.

\begin{abstract}
The impact of the COVID-19 pandemic is very concerning for the community both in terms of income and in terms of daily activities. One of the efforts to prevent the outbreak of COVID-19 is to follow the health protocols that have been set by the government, including using masks, hansanitiser, and washing hands with soap. The group of citronella farmers took the initiative to process citronella from their plantations into hansanitiser products and hand soap. The problem faced by the citronella farmer group is the lack of knowledge about technology and processing of citronella oil, besides the high price of distillation equipment that can produce good yields of essential oils. Therefore, the solution to the problems faced by citronella farmers is to design and manufacture a citronella distillation machine technology and its derivative products to later serve as a medium for making hand sanitizer and hand soap as a form of participation in preventing the spread of COVID-19 in the village. Pambang Bay. The training provided was in the form of using a citronella distillation device that had been donated, then continued with training in the manufacture of hand sanitizers and hand washing soap with raw materials from the distillation of citronella.
\end{abstract}

Keywords: Distillation, Fragrant Lemongrass, Handsanitiser, Hand Washing Soap.

\section{PENDAHULUAN}

Kabupaten Bengkalis adalah salah satu kabupaten di Provinsi Riau, Indonesia. Wilayahnya mencakup daratan bagian timur Pulau Sumatera dan wilayah kepulauan, dengan luas adalah 7.793,93 $\mathrm{km}^{2}$. Ibu kota kabupaten ini berada di Bengkalis tepatnya berada di Pulau Bengkalis yang terpisah dari Pulau Sumatera. Bengkalis mempunyai iklim tropis yang sangat dipengaruhi oleh iklim laut dengan temperatur $26^{\circ} \mathrm{C}-32{ }^{\circ} \mathrm{C}$. Musim hujan biasa terjadi sekitar bulan September-Januari dengan curah hujan rata-rata berkisar antara 809-4.078 mm/tahun. Periode musim kering (musim kemarau) biasanya terjadi antara bulan Februari hingga Agustus. 
Dengan intensitas curah hujan yang sedang tersebut membuat Bengkalis menjadi daerah strategis di bidang pertanian. Serai wangi merupakan salah satu hasil komoditi perkebunan yang memiliki nilai ekonomis yang cukup tinggi di antara tanaman perkebunan lainnya dan berperan penting sebagai sumber devisa negara.

Tanaman serai wangi merupakan salah satu tanaman penghasil atsiri yang cukup penting di Indonesia. Minyak serai wangi merupakan salah satu minyak atsiri yang diperoleh dari bagian daun dan batang tanaman serai wangi. Kualitas minyak serai wangi ditentukan oleh karakteristik alami dari minyak tersebut dan bahan-bahan asing yang tercampur di dalamnya. Apabila tidak memenuhi persyaratan mutu, harga jual minyak akan sangat murah (Kementerian Pertanian, 2013) (Anny Sulaswatty dkk, 2019). Minyak serai wangi yang berasal dari Cymbopogon nardus juga sering digunakan sebagai pewangi, disamping itu minyak ini memiliki beberapa khasiat diantaranya sebagai anti bakteri, anti jamur dan mencegah atheromatosis. Berkembangnya zaman, tanaman serai wangi banyak digunakan sebagai bahan utama pewangi pada detergen, sabun, dan lotion, dan saat pandemi COVID-19 masyarakat mulai mengolah minyak serai wangi hingga sabun cuci tangan.

Mewabahnya penyebaran COVID-19 di Negara ini menyebabkan perekonomian Negara mengalami resesi. Imbasnya terlihat jelas pada masyarakat, daya beli masyarakat berkurang, dan aktivitas pergerakan manusia juga terbatas. Kelompok mitra tani sejahtera salah satu kelompok yang terkena dampak COVID-19 ini, mereka mengalami penurunan penghasilan dari usaha tanaman serai wangi yang di gelutinya. Penurunan penjualan terjadi semenjak awal januari 2020. Berbagai upaya dilakukan untuk tetap mempertahankan kelompok tersebut. Tapi harga daun serai wangi turun drastis dari 500 rupiah perkilonya menjadi 200 rupiah perkilonya. Oleh karena itu kelompok mitra ingin mengolah serai wangi ini menjadi handsanitiser dan sabun cuci tangan dalam upaya membantu pencegahan COVID-19. Permasalahan yang dihadapi kelompok petani serai wangi adalah minimnya pengetahuan tentang teknologi dan pengolahan minyak serai wangi, selain itu mahalnya harga alat destilasi yang bisa menghasilkan randemen minyak atsiri yang bagus. Oleh karena itu, solusi dari permasalahan yang dihadapi para petani serai wangi adalah akan dirancang suatu teknologi mesin destilasi serai wangi dan alat pengolah produk turunannya untuk nantinya dijadikan sebagai media untuk pembuatan handsanitaiser dan sabun cuci tangan sebagai bentuk partisipasi dalam mencegah penyebaran COVID-19 di Desa Teluk Pambang.

Teknologi destilasi yang akan dibuat menggunakan sistem uap, dengan bahan bakar kayu campur. Produksi minyak serai wangi dilakukan melalui proses distilasi uap/air atau dikenal di masyarakat dengan istilah penyulingan selama 3-4 jam (Anny Sulaswatty dan Indri Badria Adilina, 2019). Teknologi destilasi terdiri dari tiga komponen penting yaitu, Boiler sebagai penghasil uap yang nantinya akan mangalirkan uap ke Tabung destilator yang berfungsi sebagai tempat masuknya bahan baku, Boiler menghasilkan uap air yang memiliki tekanan tinggi. Apabila terjadi kerusakan seperti kebocoran yang dapat melukai operator bahkan dapat meledak dan akan merusak lingkungan. Maka, dapat menunda proses produksi sehingga produk yang dihasilkan kualitasnya akan menurun atau rusak (Dwi Ardiyanto Effendy, dkk: 2013). Dari destilator uap yang sudah bercampur dengan uap serai wangi akan masuk ke kondensor yang berfungsi sebagai pengubah fasa, dari pasa uap menjadi fasa cair. Setelah dari kondensor cairan akan masuk keseparator untuk dipisahkan antara minyak dan air. Produk yang dihasilkan berupa minyak atsiri murni. Setelah pelatihan pengolahan minyak atsiri dilanjutkan dengan pelatihan pembuatan produk handsanitiser dan sabun cuci tangan, dengan mengundang kelompok mitra dan masyarakat Teluk Pambang. Selain itu juga kegiatan ketiga akan dilakukan pelatihan budidaya serai wangi.

Adapun tujuan kegiatan yang dilakukan berdasarkan permasalahan yang menjadi prioritas utama mitra dan dijadikan teknologi yaitu: Membuat teknologi alat destilasi serai wangi kapasitas 50-100 kg/jam. Memberikan pelatihan pembuatan handsanitiser dan sabun cuci tangan. Memberikan pelatihan tentang budidaya dan pasca panen serai wangi serta pelatihan pembuatan produk turunan serai wangi. Pelatihan bagaimana membuat kemasan dan sistem pemasaran yang baik. 


\section{METODE}

Pelaksanaan kegiatan Program Kemitraan Masyarakat (PKM) ini menghasilkan alat destilasi, produk handsanitiser dan sabun cuci tangan. Pihak-pihak yang terlibat dalam kegiatan ini diantaranya pengusul dan tim serta beberapa mahasiswa, dan satu kelompok mitra, mitra tani sejahtera, beserta beberapa elemen masyarakat Teluk Pambang. Selain itu juga pihak lain yang terlibat adalah Balitbang provinsi beserta tim sebagai narasumber dalam kegiatan ini. Kegiatan ini akan dilakukan pada 2 (dua) tempat kegiatan pelaksanaan, yaitu di Bengkel konstruksi Politeknik Negeri Bengkalis dan di Balai Desa Teluk Pambang masing-masing untuk membuat dan merakit alat destilasi serai wangi dan kegiatan pelatihan dilaksanakan di Balai desa Teluk Pambang. Setelah alat selesai dibuat langsung di aplikasikan di kelompok mitra di Jalan Sudirman Desa Teluk Pambang, Kecamatan Bantan, Kabupaten Bengkalis. Untuk mencapai hasil yang maksimal pada kegiatan PKM ini dibuatkan tahapan/metode pelaksanaan program yang dapat dilihat pada bagan alir dibawah ini:

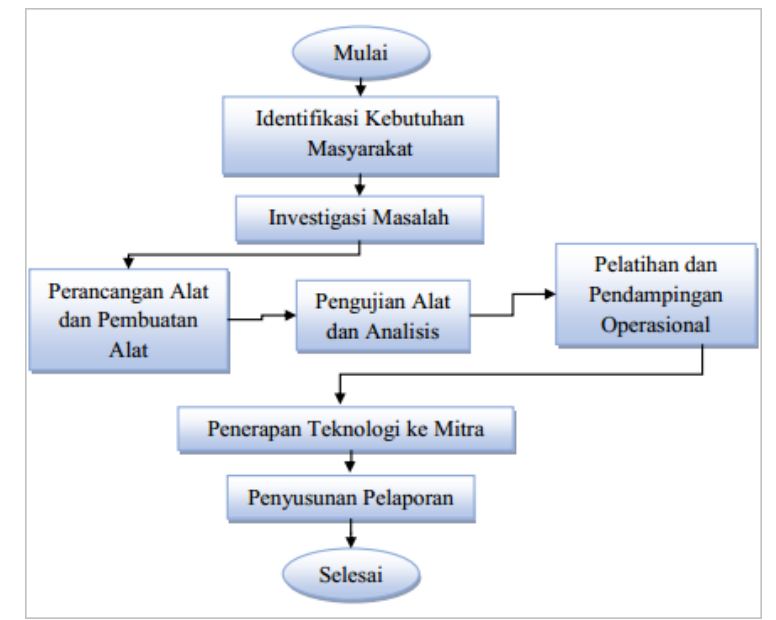

Gambar 1. Bagan Alir Pelaksanaan Program Kemitraan Masyarakat

\subsection{Identifikasi Kebutuhan Masyarakat}

Pada bagian ini pengusul bersama anggota melakukan survey ke desa tujuan Program Kemitraan Masyarakat (PKM). Kegiatan yang dilakukan berkonsultasi dengan masyarakat dan kelompok mitra bahwa mereka membutuhkan suatu teknologi alat serta solusi yang bisa membantu untuk meringankan masalah yang mereka hadapi untuk menjalankan program kelompok. Adapun beberapa kebutuhan kelompok mitra yaitu teknologi alat destilasi pelatihan pembuatan handsanitiser dan sabun cuci tangan serta beberapa pelatihan budidaya dan pasca panen serai wangi, dan pelatihan pemasaran.

\subsection{Investigasi Masalah}

Setelah melakukan survey ketua pengusul dan tim melakukan koordinasi untuk merumuskan investigasi masalah yang dihadapi oleh kelompok mitra dan kemudian menawarkan beberapa solusi alternatif, sehingga akhirnya disepakati pembuatan alat destilasi serai wangi, serta beberapa pelatihan peembuatan handsanitiser dan sabun cuci tangan, pelatihan budidaya dan pascapanen serai wangi, dan pelatihan pemasaran.

\subsection{Perancangan dan Pembuatan Alat}

Setelah dirumuskan masalah dan ditemukan solusi, dimulailah perancangan alat dengan membuat gambar desain alat satu persatu. Alat dibuat satu persatu dimulai dari alat destilasi dengan kapasitas 50-100 kg/jam dengan bahan stainlees steel dengan menggunakan sistem uap Boiler yang berbahan bakar kayu, dengan produksi $100 \mathrm{~kg}$ daun serai wangi menghasilkan minimal $1 \mathrm{~kg}$ minyak serai wangi. Setelah itu membuat desain alat pengolah produk turunan serai wangi dan membuat rencana pelatihan dan pendampingan yang akan dibuat. Setelah 
selesai membuat gambar, dilakukan proses pembelian bahan. Pekerjaan ini dilakukan oleh ketua dan anggota pengusul dengan bantuan seorang teknisi dan dua orang pembantu lapangan serta dua orang mahasiswa teknik mesin di Laboratorium Konstruksi Jurusan Teknik Mesin.

\subsection{Pengujian Alat dan Analisis}

Proses selanjutnya adalah pengujian alat, setelah selesai dibuat dilakukan uji coba alat dengan mengoperasikan alat. Alat diuji cobakan dengan bahan baku yang telah disediakan. Gambar 9 merupakan kegiatan pengujian yang telah dilakukan dengan menggunakan $100 \mathrm{~kg}$ serai wangi. Permasalahan yang dihadapi saat melakukan proses pengolahan adalah air yang masuk ke Boiler belum bisa maksimal, disebabkan tekanan spesifikasi pompa tidak bisa menahan tekanan diatas 2 bar. Proses pengolahan hingga menjadi minyak atsiri masih tetap bisa dilakukan dengan tekanan operasi dibawah 2 bar.

\subsection{Serah terima alat dan pelatihan kepada mitra}

Setelah alat selesai dibuat dan diuji maka tahapan selanjutnya adalah menyerahkan alat kepada mitra dan melakukan pelatihan penggunaan alat,pelatihan budidaya pasca panen serai wangi, pelatihan pembuatan produk turunan handsanitiser dan sabun cuci tangan.

\subsection{Pendampingan}

Dalam kegiatan ini pengusul mendampingi mitra sampai mitra bisa mandiri baik dalam pengoperasian alat/penyulingan serai wangi maupun pengolahan produk turunan serai wangi.

\section{HASIL DAN PEMBAHASAN}

Kegiatan ini dilaksanakan selama delapan bulan mulai dari 1 maret hingga 30 Oktober. Adapun hasil dari kegiatan ini secara keseluruhan telah dicapai dengan baik dan bisa menyelesaikan segala permasalah mitra yang telah disebutkan di pendahuluan. Adapun uraian kegiatan yang dilaksanakan adalah:

\subsection{Pembuatan Alat Destilasi Serai Wangi}

Pembuatan alat destilasi serai wangi ini dibuat oleh tim pengusul bersama seorang teknisi dan pembantu lapangan beserta 4 orang mahasiswa. Dalam kegiatan ini ada 4 komponen yang dibuat diantaranya boiler sebagai penghasil uap kapasitas $100 \mathrm{~kg} / \mathrm{jam}$, kedua destilator sebagai wadah bahan baku serai wangi, ketiga kondensor sebagai media pendingin dan separator sebagai alat pemisah air dan minyak.

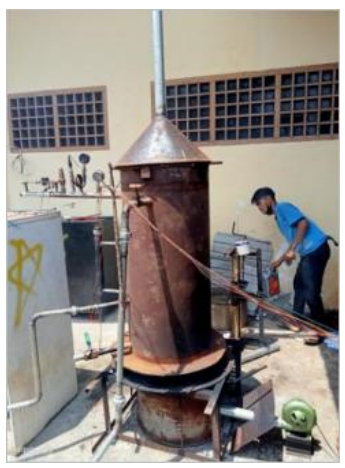

(a)

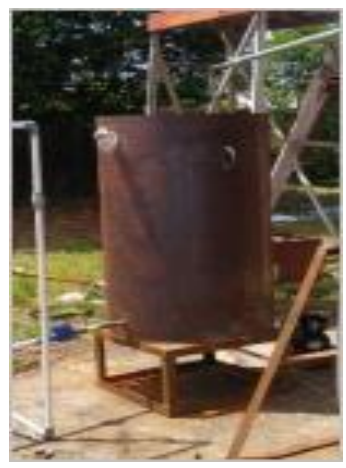

(b)

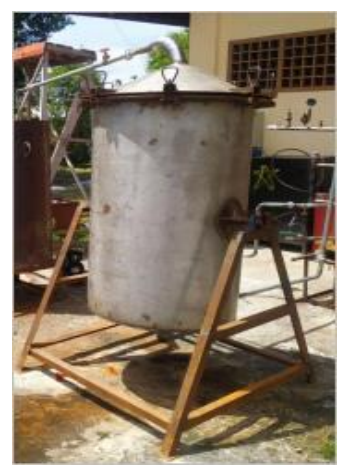

(c)

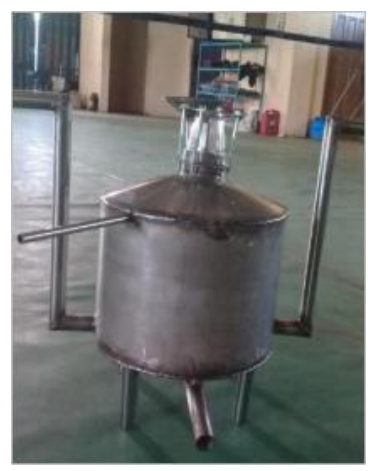

(d)

Gambar 2. (a) Boiler, (b) Kondensor, (c) Destilator, (d) Separator

Adapun prinsip kerja alat destilasi serai wangi adalah sebagai berikut: 1) Masukkan daun serai wangi kedalam tabung destilator, 2) Hidupkan kayu diruang bakar, 3) Panaskan Boiler sampai suhu mencapai 150 derajat celcius sekitar 1 jam, 4) Setelah suhu tercapai buka 
valve pipa uap yang menuju ke tabung destilator, 5) Dari tabung destilator uap akan menuju ke ruang kondensor untuk mengubah uap menjadi cair, 6) Kemudian uap yang telah berubah menjadi cair masuk ke separator untuk pemisahan antara air dan minyak menggunakan metode gravitasi, 7) Setelah itu buka keran bagian atas untuk mengambil minyak serai wangi (atsiri) 8) Proses ini berlangsung selama 5 jam, 9) Air sisa destilasi ditampung dalam drum kemudian dibuat bahan campuran untuk membuat sabun cuci tangan.

\subsection{Serah Terima Alat Destilasi Serai Wangi}

Setelah alat selesai dibuat kegiatan selanjutnya adalahmenyerahkan alat ke mitra dan memberikan pelatihan penggunaan alat kepada mitra sampai mitra bisa mandiri dan bisa mengoperasikan alat destilasi tersebut.

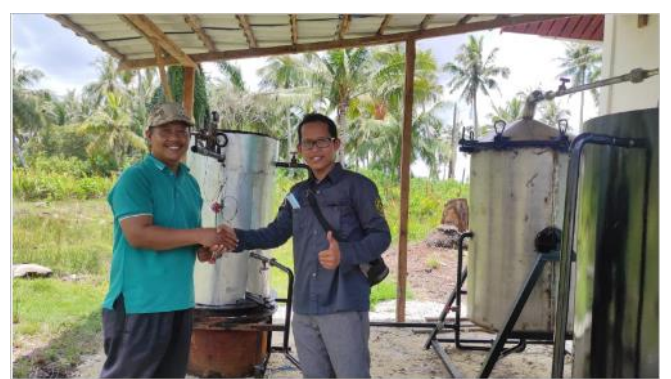

Gambar 3. Serah Terima Alat Destilasi Serai Wangi

\subsection{Pelatihan Budidaya Serai Wangi dan Pembuatan Produk Turunan Serai Wangi Berupa Pembuatan Handsanitiser dan Sabun Cuci Tangan}

Kegiatan selanjutnya adalah memberikan ilmu pengetahuan dalam bentuk pelatihan agar nantinya mitra bisa mandiri dalam mengolah hasil produksi serai wangi yang dihasilkan dalam kegiatan ini ada dua pelatihan sekaligus yang diberikan mulai dari budidaya serai wangi, dan pelatihanpembuatan handsanitiser dan sabun cuci tangan.

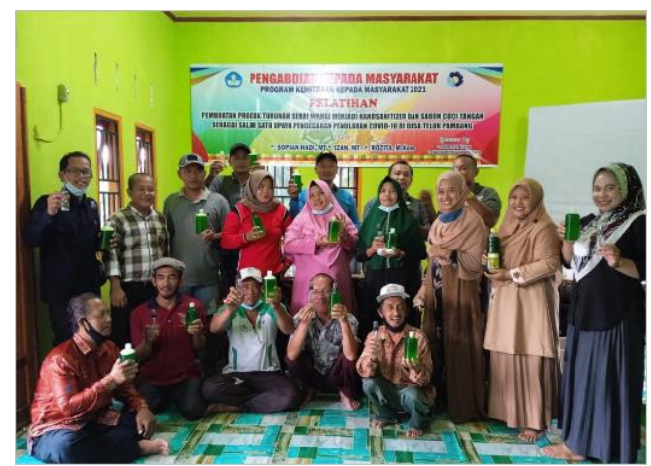

Gambar 4. Pelatihan Pembuatan Handsanitiser dan Sabun Cuci Tangan

Hasil kegiatan ini diharapkan peningkatan pendapatan masyarakat khususnya para petani serai wangi Desa Teluk Pambang dan Desa sekitar. Minyak serai wangi yang dihasilkan akan dijual dan sebagian diolah menjadi handsanitiser kemudian dijual di Desa Teluk Pambang dan mungkin bisa dijual di Perguruan tinggi asal pengusul yaitu Politeknik Negeri Bengkalis yang membutuhkan handsanitiser dan juga sabun cuci tangan untuk pencegahan penularan COVID-19, selain itu juga kedepannya mitra akan menjual produk turunan lain seperti sabun cuci piring, sabun mandi, pel lantai dan lain-lainnya.implikasi dari kegiatan ini nantinya bisa menjadi pembelajaran mahasiswa teknik mesin dalam hal alat destilasi dan mahasiswa akuntansi keuangan publik untuk pembelajaran sistem managemen keuangan dan laporan keuanga serta pemasaran produk. Mitra juga sangat antusias dan sangat membantu terselesainya program ini dengan menyediakan tempat sarana dan praasaarana untuk kegiatan ini. 


\section{KESIMPULAN}

Keseluruhan kegiatan pengabdian kepada masyarakat dalam program kemitraan kepada masyarakat ini dapat disimpulkan, Hasil luaran dalam kegiatan ini telah tercapai dan bisa menyelesaikan permasalahan mitra. Luaran yang dihasilkan dalam kegiatan ini adalah satu unit alat destilasi serai wangi kapasitas $100 \mathrm{~kg} /$ proses.

Kegiatan pelatihan telah dilaksanakan diantaranya pelatihan pengoperasian alat destlasi serai wangi, pelatihan budidaya serai wangi, pelatihan pembuatan produk turunan handsanitiser dan sabun cuci tangan, cara pembuatan labelproduk hingga metode pemasaran.

Hasil kegiatan ini memiliki dampak positif bagi kelompok dan masyarakat sekitar. Hal ini dilihat dari indikator minat masyarakat untuk menanam serai wangi di pekarangan rumahnya dan lahan tidur yang ada. Pada akhirnya nanti masyarakat Teluk Pambang bisa memproduksi serai wangi dan produk turunan untuk dijual dan digunakan sendiri.

\section{UCAPAN TERIMA KASIH}

Terima kasih sebesar-besarnya kepada DRPM Kemendibudristek yang telah memberikan dukungan finansial terhadap kegiatan ini. Terima kasih juga kepada Politeknik Negeri Bengkalis yang telah memfasilitasi perlengkapan dan peralatan dalam proses pembuatan alat, dan pihak Desa Teluk Pambang, BUMDesa Teluk Pambang dan kelompok Tani Sejatera serta ibu-ibu PKK.

\section{DAFTAR PUSTAKA}

Anny Sulaswatty, M.S. (2019). QUO Vadis Minyak Serai Wangi dan Produk Turunanny. Jakarta: Lembaga Ilmu Pengetahuan Indonesia (LIPI).

Aviasti Anwar, d. (2016). Teknologi Penyulingan Minyak Sereh Wangi Skala Kecil dan Menengah di Jawa Barat. Teknoin,22, 664-672.

Anwar, A., Nugraha, N., Nasution, A., \& Amaranti, R. (2016). Teknologi Penyulingan Minyak Sereh Wangi Skala Kecil dan Menengah di Jawa Barat. Teknoin, 22(9).

Feriyanto, Y. E., Sipahutar, P. J., Mahfud, M., \& Prihatini, P. (2013). Pengambilan Minyak Atsiri dari Daun dan Batang Serai Wangi (Cymbopogon winterianus) Menggunakan Metode Distilasi Uap dan Air dengan Pemanasan Microwave. Jurnal Teknik ITS, 2(1), F93-F97.

Luthfi, M., Winarso, R., \& Wibowo, R. (2018). Rancang Bangun Boiler Dan Tangki Penguapan Minyak Atsiri Pada Mesin Destilator Dengan Metode Uap Berbahan Baku Daun Serai (Cymbopogon Nardus). JURNAL CRANKSHAFT, 1(1).

Tristhy Novilia Angesti, (1995), "Perbandingan rendemen dan komponen minyak atsiri sereh wangi," no. 06, p. 39-53.

W. Bota, M. Martosupono, dan S. Ferdy Rondonuwu, K. Kunci, and M. Sereh Wangi, (2015), "Potensi Senyawa Minyak Sereh Wangi (Citronella Oil) Dari Tumbuhan Cymbopogon Nardus L. Sebagai Agen Antibakteri," Semin. Nas. Sains dan Teknol. Fak. Tek. Univ. Muhammadiyah Jakarta, no. November, pp. 1-8.

Harfit, A. R. (2020). Analisa Hasil Simulasi Perancangan Konstruksi Boiler Untuk Pengolahan Tahu. Jakarta: Universitas Gunadarma Fakultas Teknologi Industri

Ihsan, S. (2019). Kajian Teoritis Perencanaan Boiler Pipa Api Pada Usaha Kecil Vulkanisir. Jurnal Teknik Mesin, 8, 30-32

Jayanudin. "Proses Penyulingan Minyak Atsiri Dengan Metode Uap Berbahan Baku Daun Nilam." Jurusan Teknik Kimia, n.d.: 67-75 